\title{
Estimation of stature from middle finger length
}

\author{
Vishal Koulapur ${ }^{1, *}$, Bhuyyar Chandra Sekhar ${ }^{2}$, Rinku Porwal ${ }^{3}$, Kashif Ali ${ }^{4}$, RS Honnungar $^{5}$, SS Pujar $^{6}$ \\ ${ }^{\mathbf{1 , 6}}$ Associate Professor, ${ }^{4}$ PG Student, ${ }^{5}$ Professor, KLE University, JN Medical College, Belgaum, ${ }^{2}$ Assistant Professor, BM Patil \\ Medical College, Bijapur, ${ }^{3}$ Assistant Professor, Dept. of Forensic Medicine \& Toxicology, Shaikh Homeopathic Medical \\ College, Belgaum
}

*Corresponding Author:

Email: drvishalk@gmail.com

\section{Introduction}

Identification determines the individuality of a person. It is determined by physical characteristics like age, sex, race, stature, etc. Stature is one of the primary data for identification. Stature estimation occupies a central position in identification done by the medicolegal expert and also in anthropology. In cases where only the parts of body are available and the body is not in its entirety, stature estimation and thus establishing identity becomes a challenging task. ${ }^{(1)}$ Significant correlations have been found between stature and different body (anthropometric) measurements, long bone lengths etc. of a person. This principle helps to establish the stature and thus the partial identity of a person in natural and manmade mass disaster cases like earth quakes, cyclones, tsunamis, floods, bomb blasts and airplane accidents where in fragmented and mutilated body parts are available.

Previous works on stature estimation which are available are applicable to only one population group and cannot be generalized to other populations because of variations in genetic and environmental factors, so it becomes necessary to have stature estimation methods to the different ethnic groups. ${ }^{(2)}$ Many studies are done to calculate stature from foot length, limb length, and long bones but only few studies are available on finger lengths. The middle finger length shows a significant correlation with the stature, so in the present study an effort has been made to evolve a regression equation to calculate stature from middle finger lengths using statistical methods in the north Karnataka region as there is no such data available. This will be helpful in conditions where only a hand or a part of hand is available for identification of a person.

\section{Materials and Method}

A cross-sectional study was done over a period of one year from $1^{\text {st }}$ April 2016 to $31^{\text {st }}$ March 2017. During this period, 150 individuals i.e. 75 males and 75 females, born and brought up in the North Karnataka region of India (Districts included were Belgaum,
Dharwad, Bijapur, Gulbarga, Bagalkot, Gadag and Haveri) of the age above 21 years were chosen for the study. Age above 21 years was chosen for the reason that by this age nearly all secondary centers fuse with the respective shafts. Those who were not born and brought up here were excluded. To minimize error, cases of dwarfism, gigantism and those having skeletal abnormality of spine and long bones were excluded from the study. Informed written consent was obtained prior to recording the measurements. All measurements were taken in a well-lighted room in day light and a single person to prevent inter-observer bias.

Anthropometric measurements and techniques: measurements of middle finger length of males and females were taken by using a Vernier caliper and the stature was recorded using an anthropometer rod set. Stature was measured as vertical distance from the vertex to the floor. Measurement was recorded by making the subject to stand erect on a horizontal resting plane, bare footed with shoulder blocks and buttocks touching the wall. Anthropometer was placed in straight vertical position in front of the subject with head oriented in eye-ear-eye plane (Frankfurt plane). The movable rod of the anthropometer is brought in contact with vertex in the mid sagittal plane. To measure the finger length the subject is asked to place the hands on a flat table, palms of hand were turned inwards and fingers horizontally pointing downwards and the distance between the phallangions and dactylions of the respective fingers was recorded using a Vernier caliper

\section{Observation and Findings}

The maximum, minimum and average statures of different sexes along with their maximum, minimum and average inter-acromial lengths were calculated.

The regression formulae, standard errors, standard deviations and coefficient of co-relations of the above data were computed using statistical methods by presuming $\mathrm{X}$ as an independent variable and $\mathrm{Y}$ as dependent variable. 
Table 1: Correlation between Height (stature) with Left and right finger length (cms) in total, male and female samples by Karl Pearson's correlation coefficient

\begin{tabular}{|l|l|c|c|c|}
\hline \multirow{2}{*}{ Samples } & \multicolumn{1}{|c|}{ Variables } & \multicolumn{2}{c|}{ Correlation between Height (stature) with } \\
\cline { 2 - 5 } & & $\mathbf{r}(\mathbf{X}, \mathbf{Y})$ & t-value & p-value \\
\hline \multirow{2}{*}{ Total } & Left finger length & 0.4651 & 3.6399 & $0.0007^{*}$ \\
\cline { 2 - 5 } & Right finger length & 0.3793 & 2.8398 & $0.0066^{*}$ \\
\hline \multirow{2}{*}{ Male } & Left finger length & 0.6342 & 5.6822 & $0.0001^{*}$ \\
\cline { 2 - 5 } & Right finger length & 0.5490 & 4.0790 & $0.0004^{*}$ \\
\hline \multirow{2}{*}{ Female } & Left finger length & 0.4651 & 3.6399 & $0.0007^{*}$ \\
\cline { 2 - 5 } & Right finger length & 0.3793 & 2.8398 & $0.0066^{*}$ \\
\hline
\end{tabular}

$* \mathrm{p}<0.05$

Table 2: Simple linear regression analysis of Height (stature) by Left and right finger length (cms) in total, male and female samples

\begin{tabular}{|l|l|c|}
\hline \multicolumn{1}{|c|}{ Samples } & \multicolumn{1}{|c|}{ Independent variable } & Coefficients \\
\hline \multirow{5}{*}{ Total } & Intercept & 81.19 \\
\cline { 2 - 3 } & Left finger length & 11.19 \\
\cline { 2 - 3 } & Intercept & 80.61 \\
\cline { 2 - 3 } & Right finger length & 11.27 \\
\hline \multirow{5}{*}{ Males } & Intercept & 104.67 \\
\cline { 2 - 3 } & Left finger length & 8.34 \\
\cline { 2 - 3 } & Intercept & 99.57 \\
\cline { 2 - 3 } & Right finger length & 9.06 \\
\hline \multirow{5}{*}{ Femles } & Intercept & 108.79 \\
\cline { 2 - 3 } & Left finger length & 6.89 \\
\cline { 2 - 3 } & Intercept & 119.19 \\
\cline { 2 - 3 } & Right finger length & 5.37 \\
\hline
\end{tabular}

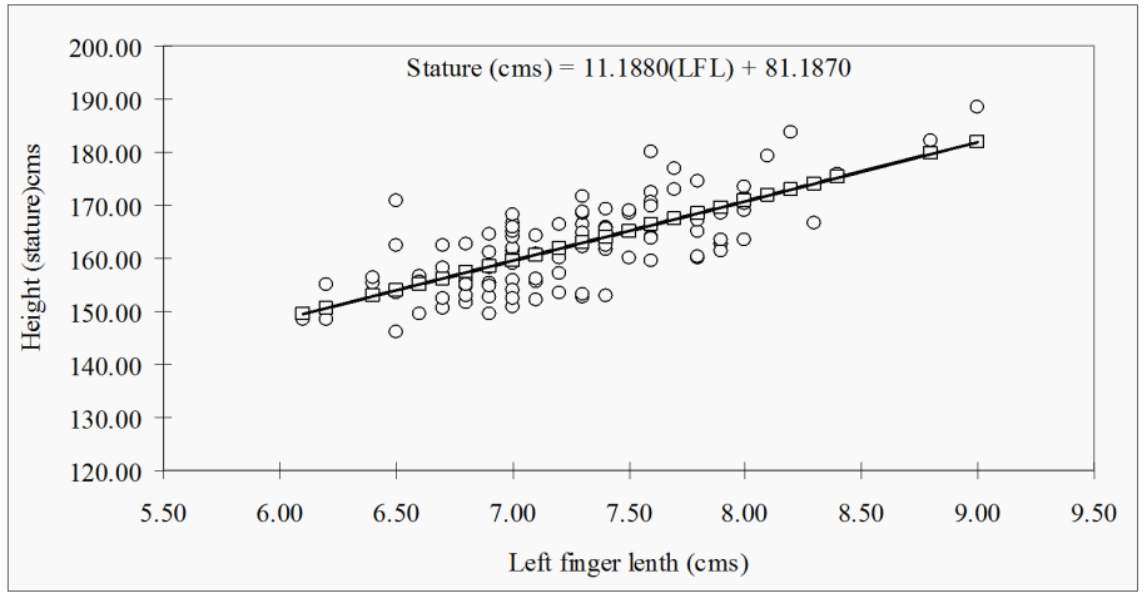

Fig. 1: Linear relationship between Height (stature) by Left finger length (cms) as a whole 


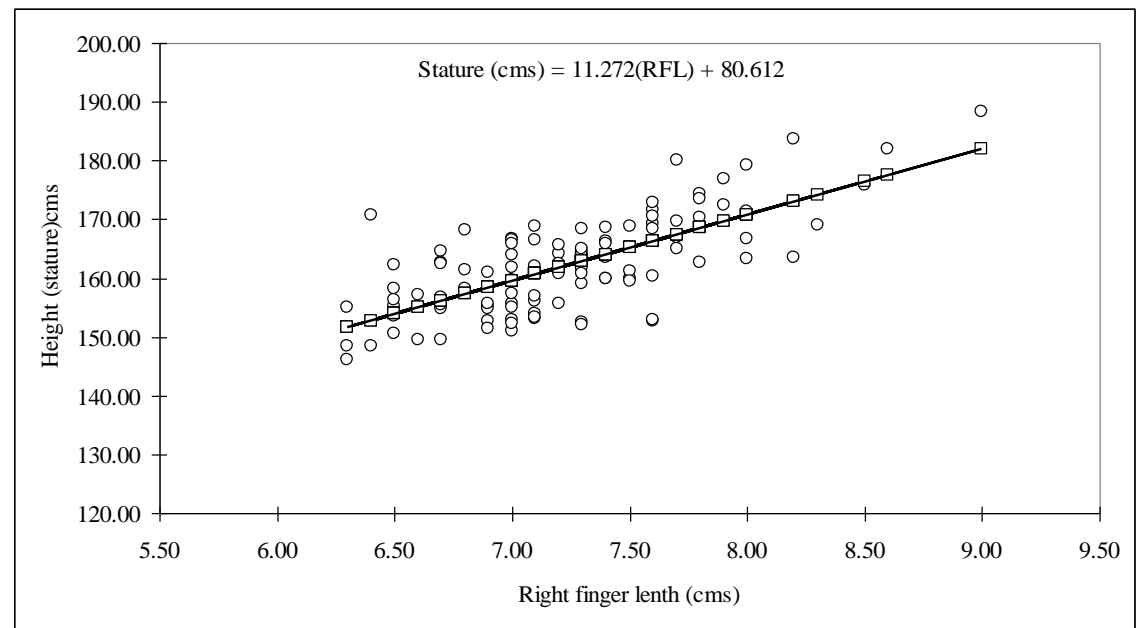

Fig. 2: Linear relationship between Height (stature) by right finger length (cms) as a whole

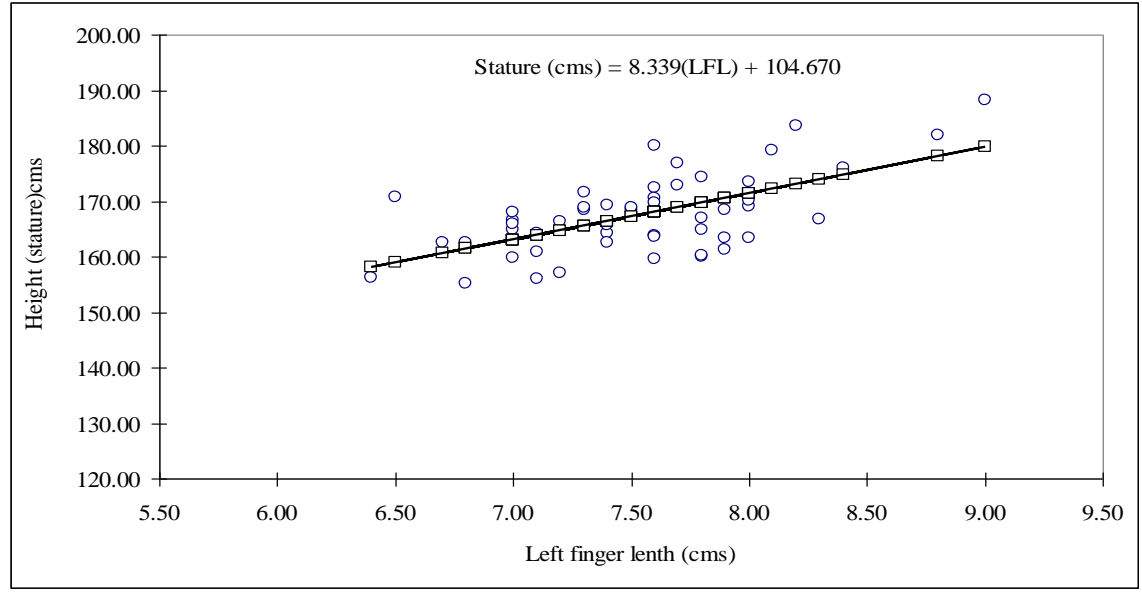

Fig. 3: Linear relationship between Height (stature) by Left finger length (cms) in males

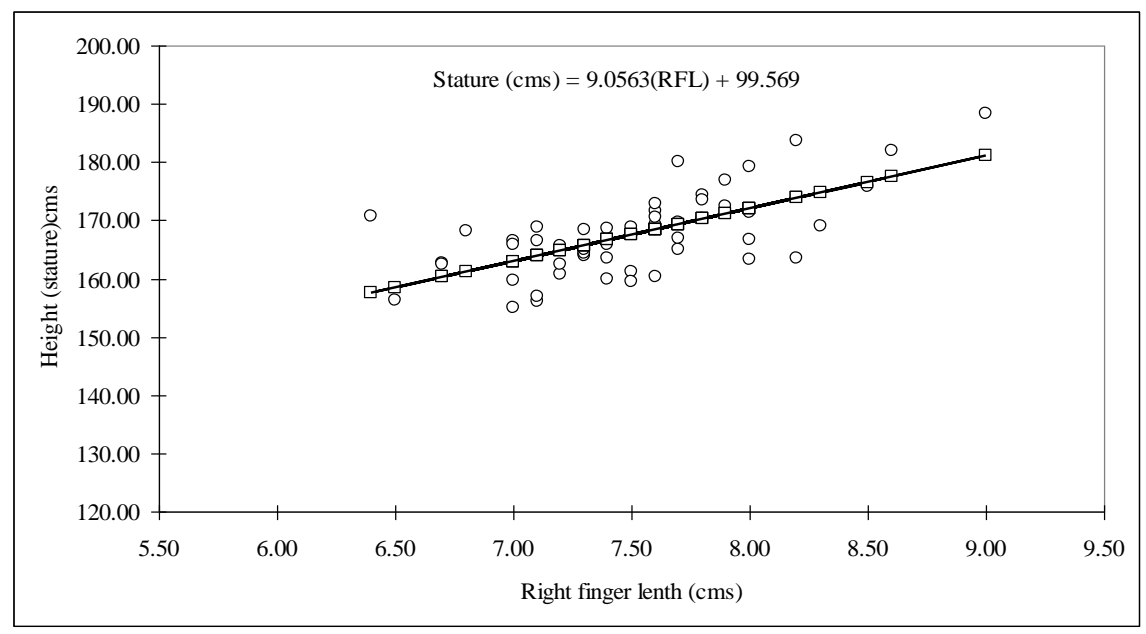

Fig. 4: Linear relationship between Height (stature) by right finger length $(\mathrm{cms})$ in males 


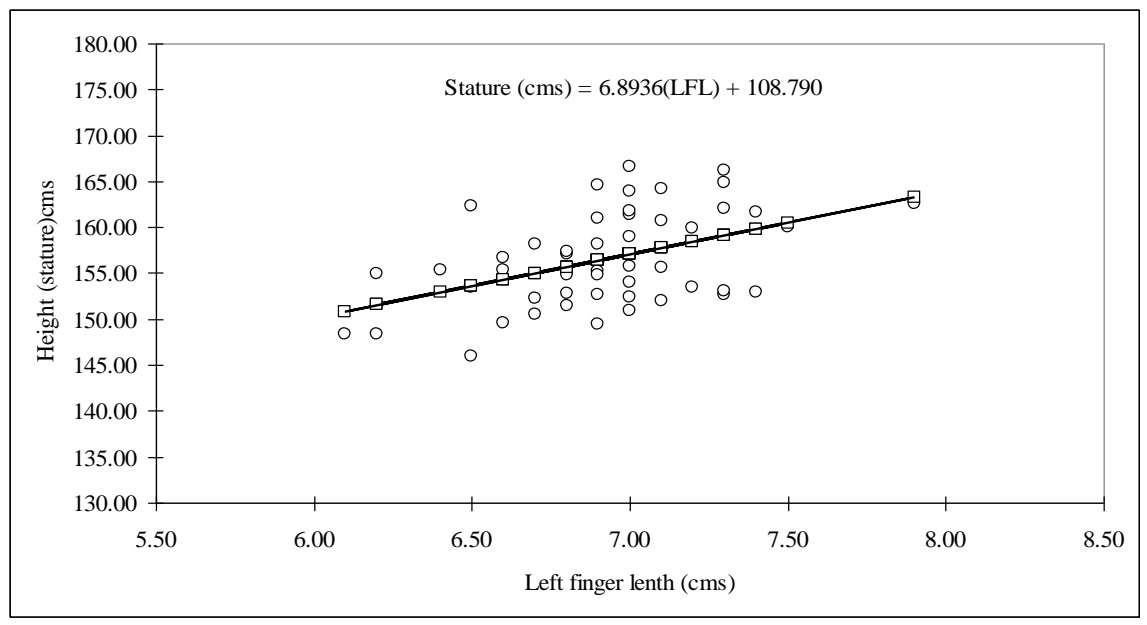

Fig. 5: Linear relationship between Height (stature) by Left finger length (cms) in females

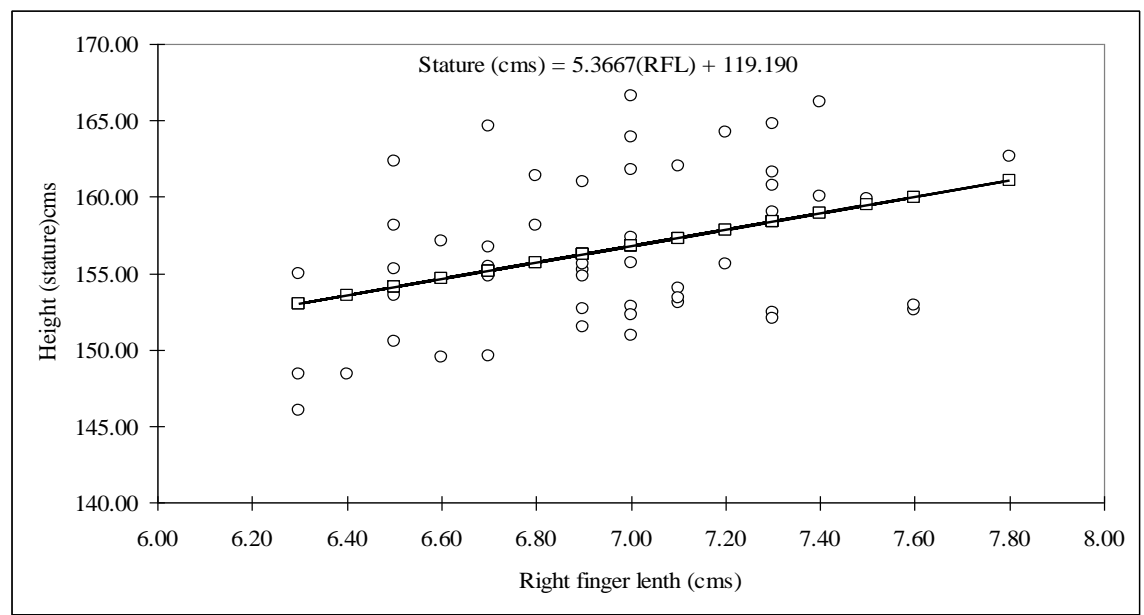

Fig. 6: Linear relationship between Height (stature) by right finger length (cms) in females

Table 3: Comparison of male and females with different variables by $t$ test

\begin{tabular}{|l|c|c|c|c|c|c|}
\hline \multirow{2}{*}{ Variables } & \multicolumn{2}{c|}{ Males } & \multicolumn{2}{c|}{ Female } & t-value & \multirow{2}{*}{ p-value } \\
\cline { 2 - 5 } & Mean & Std. Dev. & Mean & Std. Dev. & & \\
\hline Left finger length & 7.55 & 0.53 & 6.92 & 0.35 & 7.1067 & $0.0001^{*}$ \\
\hline Right finger length & 7.51 & 0.52 & 6.95 & 0.36 & 6.3488 & $0.0001^{*}$ \\
\hline Height (stature) & 167.59 & 7.06 & 156.48 & 5.13 & 9.0994 & $0.0001^{*}$ \\
\hline
\end{tabular}

$* \mathrm{p}<0.05$

\section{Discussion}

In the present study, we found good correlation between middle finger length and stature in both male and female but the correlation coefficient was higher in females than males except in cases of right middle finger length in males. Mean predictive stature of males is 167.59 and it is 156.48 in females.

The obtained regression equations for males:

(1) Stature $=9.0563($ RMFL $)+99.569$

(2) Stature $=8.339($ LMFL $)+104.67$

And in females the regression equations are:

(1) Stature $=5.3667(\mathrm{RMFL})+119.19$

(2) Stature $=6.8936($ LMFL $)+108.79$

And the regression equations as a whole are:
(1) Stature $=11.272($ RMFL $)+80.612$

(2) Stature $=11,188($ LMFL $)+81.187$

Shivakumar et $\mathrm{al}^{(3)}$ also found good correlation and statistically highly significant correlation coefficient between middle finger length and stature among the South Indian population of Karnataka region but the regression equations obtained in this study are different from their study.

In another study conducted by Verghese A.J. et al ${ }^{(4)}$ in Mysore and surrounding region of Karnataka found significant correlation between middle finger length of both hands and stature in males and females.

Krishan K. et $\mathrm{al}^{(5)}$ in their study concluded that the index finger length and ring finger length had 
statistically significant correlation with stature of adult population of North India.

Shintaku and Furuya ${ }^{(6)}$ in their study in 1990 observed good correlation between middle finger length and stature among the Japanese population.

\section{Conclusion}

The identification of commingled mutilated remain is a challenge to forensic and anthropological experts and hence a need of studies on stature estimation from different body parts in different population groups is required. Such studies help in narrowing down the pool of possible victim matches in cases of identification from mutilated remains.

The present study indicates that middle finger length can be effectively used for estimation of stature in both males and females. Many authors have insisted the need for population specific stature estimation formulae. In this study we have derived regression equations to estimate stature from middle finger length for North Karnataka region.

\section{References}

1. Pramod Kumar GN, Raghavendra Babu YP, Madhu B, Prateek Rastogi, Roopa Urs AN, Balaraj BM. Middle finger length- A Tool for Stature Estimation. JKAMLS 2014;23(2):4-8.

2. Khan F, Vaswani VR, Pramod KL, Badiadka KK. Estimation of stature from middle finger length among college students in Mangalore. International Journal of Recent Trends in Science and Technology 2016;18(3):384-387.

3. Shivkumar AH, Raju GM, Vijaynath V. Prediction of stature by right middle finger length of males among South Indian population. Journal of Pharmaceutical and Scientific Innovation 2013;2(1):31-33.

4. Verghese AJ, Balaraj BM, Pramod Kumar GN. A study of estimation of stature from length of fingers in Mysore. Indian Journal of Forensic Medicine Toxicology 2010;4(2):12-13.

5. Kanchan T, Krishan K, Sharma A, Menezes RG. A study of correlation of hand foot dimensions for personal identification in mass disasters. Forensic Sci Int 2010;199(1-3):112-116.

6. Shintaku K, Furuya Y. Estimation of stature based on the proximal phalangeal length of Japanese women's hands. JUEOH 1990;12:215-19. 